\title{
VOLUME VISUALIZATION OF WATER QUALITY DATA IN HAMILTON HARBOUR, LAKE ONTARIO
}

\author{
Efraim Halfon \\ National Water Research Institute \\ Canada Centre for Inland Waters, Burlington, Ontario, Canada L7R 4A6, \\ Tel.905-336-4917; fax 905-336-4972; E-mail: efraim.halfon@ cciw.ca
}

\begin{abstract}
Visualization in the physical and natural sciences is distinguished by the need to deal with data sets that are volumetric, time varying and multi-variant. The goal of this project is implementation of a system whereby researchers can access, analyze, and visualize water quality data collected in three dimensions (geographical co-ordinates and depth). Using computer graphics it is now possible to combine data, their three dimensional location and lake topography to create images of water quality patterns which supersede conventional surface, two dimensional, graphics (GIS). Through solid modelling, oxygen and temperature data collected on May 28, 1990 and August 8, 1990 in Hamilton Harbour, Lake Ontario, are mapped into voxels and visualized on a two dimensional screen. The calculation of the 3D representation allows the accurate computation of volumetric properties since each voxel has water quality values associated with it and these values can be summed or elaborated numerically as needs arise. For example the lake has a volume of $253,947,500 \mathrm{~m}^{3}$, the water mass (May 28, 1990) at 12-13 ${ }^{\circ} \mathrm{C}$ had a complex three dimensional shape with a volume of $61,036,250 \mathrm{~m}^{3}$ and on August $8,66 \%$ of the lake volume had oxygen levels over $4 \mathrm{mg} \mathrm{L}^{-1}$ and suitable for fish growth, contrary to expectations. A third benefit of visualization is that the data can be viewed interactively from different viewpoints thus increasing the interaction between scientist and the data.
\end{abstract}

\section{Keywords}

Volume, visualization, lake, aquatic, 3d, Hamilton Harbour, Lake Ontario, temperature, oxygen, water quality, bathymetry, graphics

\section{INTRODUCTION}

This project investigates and compares different approaches to visualization of sampled volumetric data collected in lakes and in particular in Hamilton Harbour, Lake Ontario. The interpolation of 3D data, the mapping from numeric data to visual parameters such as colour and transparency are discussed. 
Encouragement to more fully utilize time-varying, multi-dimensional data from Hamilton Harbour and other areas of concern is a further objective.

Hamilton Harbour is located at the western end of Lake Ontario, it has a triangular shape with maximum dimensions eight kilometres from east to west and five kilometres from north to south; the maximum depth in the middle of the bay is about 26 metres and an additional deep area is located at the east end. A ten metre deep channel connects it to Lake Ontario. Hamilton Harbour has been widely studied in the past ten years (Charlton, pers. comm.) since it is one of the 42 areas of concern within the Great Lakes and furthermore the International Council for Local Environmental Initiatives has designated the city of Hamilton as Canada's model city under the United Nations Agenda 21 program (ICLEI, 1990).

The Hamilton Harbour Research project will have archived over a gigabyte of heterogeneous image data by the end of this year. Other sites are similarly amassing large, complicated data sets which ecologists want to transform into useful information to provide new insight into long-term ecological phenomena. Unfortunately, the procedures, software tools, and user friendly interfaces necessary to facilitate access to these data sets are currently lacking which precludes analysis and subsequent visualization by ecologists.

In traditional (pre 1970) computer graphics, polygons and lines (e.g., a wireframe) represented three dimensional (3D) volumetric objects but some 3D data sets, e.g., the volumetric water quality patterns collected in a lake, might not consist of surfaces and edges at all. As a result, Greenleaf et al. (1970) were the first to introduce new methods of visualization to extract information from volume data. This process called volume visualization is defined by Kaufman (1992) as "a direct technique for visualizing volume primitives without any intermediate conversion of the volumetric data set to surface representation."

The first applications were in medical imaging and they are still dominant (e.g., Adams $e$ t al., 1990; Rhodes et al., 1987). McCormick et al. (1987) stated that volume visualization was emerging as a new visualization environment in scientific computing; for example Hibbard and Santek (1989) presented interesting uses in the earth sciences.

Kaufman (1991a) provided an insight into this technology stating that "the objective of volume visualization is to peer inside the volumetric objects to view that which is not ordinarily viewable and to probe into the voluminous and complex structures and their dynamics to comprehend that which is not ordinarily comprehensible." Halfon et al. (1993), Assel et al. (1994), and Halfon and Howell (1995) recently presented two dimensional computer visualizations of limnological data.

Here, a framework is described to visualize and interpret 3D data. In this framework there are three steps: data collection, solid modelling or transformation of the data in a specific volumetric format, and finally volume rendering or the visualization process. For general applications consult Kaufman (1991b), Foley et al. (1991) and Bergeron and Kaufman (1994).

Data

Water quality data (water temperature, oxygen concentration, conductivity, $\mathrm{pH}$, etc.) have been collected by Charlton (pers. comm.) every year since 1985 at 26 stations (the number of stations has slightly increased or decreased over the years). 


\section{Solid modelling}

This area of computer graphics has arisen following the need for modelling objects as solids (Foley $e t$ al., 1991). A lake is a volumetric object and each point in the lake has the value of a water quality variable (e.g., temperature, $\mathrm{pH}$, etc.) associated with it. The "point", or cell, in the lake is of course related to the resolution used in the computer representation and the cells are a collection of adjoining nonintersecting solids. When the cells are equal and arranged in a fixed, regular grid, they are called voxels (volume elements), analogous to pixels. Each voxel is a quantum unit of volume and has a numeric value (or values) associated with it that represents some measurable properties) and the 3D volumetric data set resides in an integer grid of voxels called a cubic frame buffer.

The visualization process consists of several steps necessary to organize the data in the proper voxel format: A first step is to divide the area of interest into a grid; the grid chosen for Hamilton Harbour is $50 \times 50$ metres. The depth value in each grid unit was obtained by interpolation using the SAS contouring program and the bathymetric data, which were originally in sparse form, were organized into a fixed grid.

Following the grid pattern, each voxel was defined as a rectangular parallelepiped (which allows for resolution in the different axes) with dimensions 50 metres $\mathrm{x} 50$ metres by 0.5 metres and the cube frame buffer has dimensions of $200 \times 127 \times 52$ for a total of $1,320,800$ voxels. Over 2,500 bathymetry data and 14,000 shoreline data are available from the Canadian Hydrographic Service. The choice of the number of voxels and their size is left to the user for several reasons: As the number of cells increases, grid size diminishes, the ambiguity between land and water voxels decreases, but it does not disappear, unless the lake is a perfect cube (unlikely). However, the larger the number of voxels the larger is the computer memory requirement and the computing time.

The second step was to identify which voxels represent land (depth value of zero) and which water (grid depth value greater than zero). Out of the 1,320,880 voxels only 204,034 are water given the conical shape of the harbour. A 3D array was created where each land voxel was assigned a value of zero and each water voxel a value of one. A similar procedure was followed with the water quality data. Since voxels have dimensions of cubic metres and data collected along the depth axis have already a metric dimension associated with them (data collected at $.1, .2, \ldots$, etc. metres), station locations were converted from geographical to UTM coordinates [metres] before the interpolation was performed.

Interpolation of the water quality data from scattered stations to a uniform grid was performed using water quality parameter data collected at the nearest three stations. Weight factors were inversely proportional to the square of the distance from the three closest stations. Interpolation was performed in two dimensions, one layer at the time. Interpolation in the vertical axis was performed using the IMSL (1987) subroutine SCAKM which uses a spline function to interpolate the data. A spline interpolation could not be used in the horizontal plane since the IMSL subroutine SURFER could not be constrained to have the interpolated data stay within the observed range. The interpolation problem, that is fitting the data collected at arbitrarily located positions to a uniform grid is complex. While this problem has not been fully solved, Foley et al. (1993) have reviewed past work and proposed solutions.

The third step was to join the voxels with their water quality values through Boolean algebra, this process has been defined by Manley and Tallet (1990) as "clipping."

\section{Volume rendering}

Kaufman (1991) states that "to visualize the volume data set, the voxels can be projected into 2D pixel space and stored as a raster image frame in a frame buffer. This process, which is termed volume rendering (Drebin et al., 1988; Frenkel, 1989; Levoy, 1988; Upson and Keeler, 1988), involves both the viewing and the shading of the volume image." The definition of Foley et al. (1991) is that 
"volume rendering is the process of displaying scalar fields," where a scalar field is a collection of all the numbers associated with each point in a volume. In summary "volume rendering is a direct display of volume primitives without any intermediate conversion of volume data to surface representation." (Kaufman, 1991a). There is no a priori assumption that "the data consist of tangible surfaces that can be extracted and visualized." Specialized algorithms have been developed to render clouds, humans and living objects (Blinn, 1982; Herman and Udupa, 1983). The application of volume rendering techniques to limnology is therefore not complex, but it requires the data preparation explained above.

\section{Volume viewing and shading}

Kaufman's (1991b) book can be consulted for a comprehensive review to create 2D projections from the 3D volumetric data, as well as volume rendering and shading. For this application the Hamilton Harbour voxel values were stored in ASCII format and the data set was read into memory by the Spyglass ${ }^{\circledR}$ Slicer ${ }^{1}$ program (Spyglass, 1994). Slicer is a volume visualization software that can be used for scientific visualization; while the program focuses on the 3D primitives, it can also visualize the data using more traditional $2 \mathrm{D}$ primitives, such as surface rendering as slices and isosurfaces (threedimensional equivalent of contour lines).

Surface rendering is defined as "an indirect technique used for visualizing volume primitives by first converting them into intermediate surface representation and then employing conventional computer graphics techniques to render them to the screen." (Kaufman, 1992). An isosurface (Levoy, 1988 ) is a surface where the data with the same values are interpolated together, for example a thermocline can be considered a three dimensional temperature isosurface. The surface can be rendered as a transparent or solid surface. The isosurface can also be coloured according to the values of the scalar field at the surface points (Mercurio, 1991).

\section{RESULTS}

\section{Water temperature and oxygen concentrations}

Water temperature on May 28, 1990 ranged from 11.2 to $18.9{ }^{\circ} \mathrm{C}$ and oxygen concentrations ranged between 3.8 and $15.5 \mathrm{mg} \mathrm{L}^{-1}$; water temperature on August 8 ranged from 12 to $24{ }^{\circ} \mathrm{C}$ and oxygen concentrations ranged between 0 and $10.7 \mathrm{mg} \mathrm{L}^{-1}$. Figures related to this paper can be found in the anonymous FTP site (ftp.cciw.ca in the directory incoming/halfon). The file name is isess2.zip. This file contains GIF files that show the visualization of the temperature data collected on May 28, 1990 under different rendering options. A more comprehensive set of figures can be found posted on the website http://www.cciw.ca/glimr/data/limnology/intr.html.

In May the bay was heating from the west while temperature at depth was about $11^{\circ} \mathrm{C}$. One interesting feature is a convective chimney extending from the water surface to a depth of about ten metres: this water mass has a temperature of 13 to $14^{\circ} \mathrm{C}$.

The circulation of the bay is complex and Hamblin (pers. comm.) is now developing a two dimensional mathematical model of this flow field: At the surface, currents are mostly from west to east following the prevailing winds with return flow at deeper levels. At the east end of the lake surface waters cool by mixing with Lake Ontario water that enters the bay from a channel and form a

\footnotetext{
${ }^{1}$ Spyglass is a registered trademark of Spyglass, Inc.
} 
downwelling. Thus, just under the surface along the main east-west axis there is a current from west to east $^{2}$.

In August 1990 the 13 to $14{ }^{\circ} \mathrm{C}$ and 16 to $17{ }^{\circ} \mathrm{C}$ water masses are found at lower depths than in May, at about 15 and 10 metres, respectively. The water mass at the east end of the bay, $>23{ }^{\circ} \mathrm{C}$, has the same surface temperature as the western part of lake Ontario.

\section{Volumetric properties}

The 3D representation allows computation of several volumetric properties: even if the bathymetry is uneven, the total lake volume can be easily computed by multiplying 231,053 voxels by the volume of each voxel $\left(50 \mathrm{~m} \times 50 \mathrm{~m} \times 0.5 \mathrm{~m}\right.$ or $\left.1250 \mathrm{~m}^{3}\right)$ for a total of $253,947,500 \mathrm{~m}^{3}$. Other properties, laborious to calculate through standard two dimensional projections (since these water masses have complex three dimensional shapes) are, for example, the water volume at a given temperature (Table 1) and its heat content. On May 28 , the median volumetric temperature is $13^{\circ} \mathrm{C}$ while on August 8 , the median temperature is about $20^{\circ} \mathrm{C}$. The volumetric frequency distribution of temperatures is also very different on these two dates (Table 1). On August 8, 1990 the 13 to $14{ }^{\circ} \mathrm{C}$ and 16 to $17{ }^{\circ} \mathrm{C}$ water masses are found at lower depths than on May 28, at about 15 and 10 metres, respectively. The water mass at the east end of the bay, $>23^{\circ} \mathrm{C}$, has the same surface temperature as the western part of Lake Ontario.

Table 1 Heat content of Hamilton Harbour on May 28, and August 8, 1990. Each voxel has a volume of $1250 \mathrm{~m}^{3}$

May 28, 1990

$\begin{array}{lllll}\begin{array}{l}\text { Temperature } \\ \text { Range }{ }^{\circ} \mathrm{C}\end{array} & \begin{array}{l}\text { No. of } \\ \text { Voxels }\end{array} & \begin{array}{l}\text { Volume of } \\ \text { Voxels }\left[\mathrm{m}^{3}\right]\end{array} & \begin{array}{l}\text { \% of lake } \\ \text { volume [J] }\end{array} & \text { Heat Content } \\ 11-12 & 51228 & 6.4010^{7} & 25.22 & 2.0810^{15} \\ 12-13 & 48829 & 6.1010^{7} & 24.03 & 3.1910^{15} \\ 13-14 & 39688 & 4.9610^{7} & 19.54 & 2.8010^{15} \\ 14-15 & 29608 & 3.7010^{7} & 14.57 & 2.2410^{15} \\ 15-16 & 14590 & 1.8210^{7} & 7.18 & 1.1810^{15}\end{array}$

\footnotetext{
${ }^{2}$ Conductivity values in May 28, 1990 ranged between 550 and 760 with most of the water in the range 655-680 while Lake Ontario waters have an average value of about 300 (Charlton, pers. comm.).
} 


$\begin{array}{lcccc}16-17 & 12942 & 1.6210^{7} & 6.37 & 1.1210^{15} \\ 17-18 & 5775 & 7.2210^{6} & 2.84 & 5.2810^{14} \\ 18-19 & 497 & 6.2110^{5} & 0.24 & 4.8010^{13} \\ & & & & 1.4210^{16}\end{array}$

August 8, 1990

$\begin{array}{lcccc}\begin{array}{l}\text { Temperature } \\ \text { Range }\end{array} & \begin{array}{l}\text { No. of } \\ \text { Voxels }\end{array} & \begin{array}{l}\text { Volume of } \\ \text { Voxels }\left[\mathrm{m}^{3}\right]\end{array} & \begin{array}{l}\text { \% of lake } \\ \text { volume [J] }\end{array} & \text { Heat Content } \\ 12-13 & 10043 & 1.2610^{7} & 4.94 & 6.5610^{14} \\ 13-14 & 22203 & 2.7810^{7} & 10.93 & 1.5710^{15} \\ 14-15 & 15410 & 1.9310^{7} & 7.58 & 1.1710^{15} \\ 15-16 & 11474 & 1.4310^{7} & 5.65 & 9.3010^{14} \\ 16-17 & 11711 & 1.4610^{7} & 5.76 & 1.0110^{15} \\ 17-18 & 9279 & 1.1610^{7} & 4.57 & 8.4810^{14} \\ 18-19 & 6690 & 8.3610^{6} & 3.29 & 6.4710^{14} \\ 19-20 & 8083 & 1.0110^{7} & 3.98 & 8.2310^{14} \\ 20-21 & 8511 & 1.0610^{7} & 4.19 & 9.1110^{14} \\ 21-22 & 13119 & 1.6410^{7} & 6.46 & 1.4710^{15} \\ 22-23 & 50167 & 6.2710^{7} & 24.69 & 5.8910^{15} \\ 23-24 & 31019 & 3.8810^{7} & 15.27 & 3.8010^{15} \\ 24-25 & 5451 & 6.8110^{6} & 2.68 & 6.9710^{14}\end{array}$

A similar calculation can also be performed for oxygen. About $34 \%$ of the lake had oxygen levels below $4 \mathrm{mg} \mathrm{L}^{-1}$ on August 8 , and conversely, $66 \%$ of the harbour had waters suitable for fish growth. On May 28, oxygen depletion does not start at the bottom, as it could be expected, but it starts at the surface at the southern shallow part of the lake and it evolves northward in the form of chimneys.

\section{DISCUSSION}

Visualization in the physical and natural sciences is distinguished by the need to deal with data sets that are volumetric, randomly spaced, time varying and multi-variant. With this methodology limnologists can access, analyze, and visualize water quality data collected in three dimensions (geographical coordinates and depth). Manley and Tallet (1990) noted that "the ability to visually manipulate and gain quantitative information from three dimensional models ${ }^{3}$ provides more information to the researcher over a significantly shorter period of time that a myriad of cross-sections and planar maps." The process of collating the data also produces information since the properties associated with each voxel are suitable for volumetric analysis. With the development of fast personal computers and properly designed software, it is possible to visualize limnological data on a personal computer quickly once the data have been interpolated and saved in a format suitable for volume visualization. This time frame contrasts with the months needed to collect a proper data set.

\footnotetext{
${ }^{3}$ Manley and Tallet (1990) used both mathematical models as well as data to understand the system they were studying.
} 
Charlton (pers. comm.) has collected water quality data in Hamilton Harbour since 1985: After nine years of sampling, the amount of data available for analysis is quite extensive, since data are collected seven or eight times a year at over twenty-five stations at over fifty depths. The Hamilton Harbour Research project will have archived over a gigabyte of heterogeneous image data by the end of this year and the visualization tool permits a clear understanding of these data at a glance. The volumetric patterns of increasing temperature and decreasing oxygen content can be easily followed and understood. The relations between observed patterns and the complex circulations are also made evident through this approach.

Visualization showed three dimensional patterns not visible otherwise. Temperature data, for example, show the water masses present in the lake and their movement to the bay. The process of oxygen depletion can be followed in the three dimensional space and the number of voxels with given water quality properties can be easily computed for further analysis. A benefit of visualization is also that the data can be viewed interactively from different perspectives and with different viewing options thus increasing the interaction between scientist and the data.

ACKNOWLEDGMENTS

Murray Charlton provided his unpublished data collected in Hamilton Harbour. Jackie Dowell prepared the FORTRAN program to convert the data to the volume visualization format and create the appropriate masks. Robert Coker gave useful suggestions, helped with the editing and gave creative assistance in the rendering process. Spyglass corporation provided a beta version of their program Slicer.

\section{REFERENCES}

Adams, L., Gilsback, J.M., Krybus, W., Meyer-Ebrecht, D., Mosges, R. and Schlondorff, G., (1990) CAS-A navigation support for surgery. In K.H. Hoehne, H. Fuchs and S.M. Pzier (eds.) $3 D$ Imaging in Medicine: Algorithms, Systems, Applications, Springer Verlag, Berlin, 411-423.

Assel, R.A., Croley, T.E. II, and Schneider, K. (1994) Computer visualization of long-term average Great Lakes temperatures and ice cover. J. Great Lakes Res., 20, 771-782.

Bergeron, R.D. and Kaufman, A.E. (eds.) (1994) Proceedings, Visualization '94. IEEE Computer Society Press, Los Alamitos, CA.

Blinn, J.F. (1982) Light reflection functions for simulation of clouds and dusty surfaces. Computer Graphics, 16, 21-29.

Charlton, M. (1994) Pers. Comm. National Water Research Institute, Canada Centre for Inland Waters, Burlington, Ontario, Canada.

Drebin, R.A., Carpenter, L., and Hanraham, P. (1988) Volume rendering, Computer Graphics, 22, 6475 .

Foley, J.D., van Dam, A., Feiner, S.K. and Hughes, J.F. (1991). Computer Graphics: Principles and Practice, Addison-Wesley Publishing Co., Reading, Mass. 
Foley, T.A., Hagen, H. and Nielson, G.M. (1993) Visualizing and modeling unstructured data. The Visual Computer, 9, 439-449.

Frenkel, K.A. (1989) Volume rendering. Communications of the ACM, 32, 426-435.

Greenleaf, J.F., Tu, T.S. and Wood, E.H. (1970). Computer-generated oscilloscopic images and associated techniques for display and study of the pulmonary blood flow, IEEE Trans. Nucl. Sci., NS17, 353-359.

Halfon, E. and Howell, M. (1995) Visualization of limnological data as two- and three-dimensional computer generated animations. J. Biol. Systems , 4, 3-25.

Halfon, E., Tartari, G., Howell, M., and Binelli, A. 1993. Visualization and limnological interpretation of liming treatments in a deep lake, Lake Orta, Italy, using computer generated animations. In IFIP, WG 5.11 Working conference on Computer Support for Environmental Assessment, CSEIA '93, villa Olmo, Como, Oct. 6-8, 1993. pp. 37-48.

Herman, G. T. and Udupa, J.K. (1983) Display of 3D digital images: computational foundations and medical applications. Proc. Medcomp '82, IEEE Computer Society Press, 308-314.

Hibbard, W and Santek, D. (1989) Visualizing large data sets in the Earth Sciences. IEEE Computer, 22, 53-57.

ICLEI (1990) World Congress of Local Governments for a Sustainable Future, New York, 1990. International Council for Local Environmental Initiatives, World Secretariat, City Hall, East Tower, 8th Floor, Toronto, Ontario, Canada M5H 2 N2.

IMSL (1987) Math/Library ${ }^{\mathrm{TM}}$. User's manual. FORTRAN subroutines for mathematical applications. IMSL, 2500 ParkWest Tower One, 2500 CityWest Blvd., Houston, Texas 77042-3020, U.S.A.

Kaufman, A. (1991a) Introduction to Volume Visualization in A. Kaufmann (ed.) Volume visualization, IEEE Computer Society Press, Los Alamitos, California, pp. 1-18.

Kaufman, A. (1991b) Volume visualization. Los Alamitos, California: IEEE Computer Society Press, $477 \mathrm{pp}$.

Kaufman, A. 1992. Introduction to volume visualization. ACM Siggraph '92, Course Notes, 285 pp.

Levoy, M. 1988. Display of surfaces from volume data. IEEE Computer Graphics and Applications, 8, 29-37.

Manley, T.O. and Tallet, J.A. 1990. Volumetric Visualization: an effective use of GIS technology in the field of oceanography. Oceanography, 3, 23-29.

McCormick, B.H., DeFanti, T.A., and Brown, M.D. (1987) Visualization in scientific computing, Computer Graphics, 21 (special issue).

Mercurio, P.J. (1991) The data visualizer, Pixel, July/August, 31-35. 
Rhodes, M.L., Kuo, Y., and Rothman, S.L.G. (1987) An application of computer graphics and networks to anatomic model and prosthesis manufacturing. IEEE Computer Graphics, 7, 12-25.

Shirley, P and Neeman, H. (1989) Volume visualization at the center for supercomputing research and development. Proc. Chapel Hill Workshop on Volume Visualization, Univ. of North Carolina Press, Chapel Hill, N.C., pp. 17-20.

Spyglass (1994) Slice, Spyglass Inc. 1800 Woodfield Dr., Savoy, Illinois.

Upson, C and Keeler, M. (1988) V-BUFFER: Visible volume rendering, Computer Graphics, 22, 5964. 